\title{
Creating Fertile Voids: The Use of Poetry in Developmental Coaching
}

\author{
Deborah Humphrey \\ Carl Tomlinson
}

\author{
Oxford, \\ United Kingdom
}

\begin{abstract}
There has been much attention in coaching to the drawing together of models of practice from fields such as education and therapy. However, there has been less attention given to the broader use of the arts, such as poetry. Although humans have used poetry to understand ourselves for millennia, little attention has been paid to how the use of poetry can contribute to coaching, and offer different perspectives on the human condition. We take the view that clients who enter a coaching relationship are looking for opportunities to explore different perspectives for their presenting issues. Poetry has the power to enable creativity, awareness, emotion and empathy. It permits a type of exploration that is often neglected in the milieu of the everyday, thus allowing a different insight and perspective. Using poetry sensitively and creatively allows the client to search for meaning outside of a transactional dialogic approach. This approach is challenging, and the coach is required to be able to work with concepts of the felt sense and uncertainty. This paper starts to explore this approach and offer some ideas of how it can be brought in to practice.
\end{abstract}

Keywords: person-centred, developmental coaching, poetry, self-awareness, creativity

\section{Introduction}

Coaches use a variety of evidence-based techniques, often drawn from the fields of psychology, education and therapy, and they may establish themselves as experts because of one or other of these techniques. As coaching practice develops we may feel more confident about using techniques drawn from beyond these traditional fields.

This is an Open Access article distributed under the terms of the Creative Commons Attribution (CC BY) License which permits use, distribution and reproduction in any medium, provided the original work is properly cited. 
In this paper we draw on insights and evidence from literature, creativity, and therapy. We present an approach to practice that offers coaches and clients a unique insight into some issues often surfaced in coaching conversations. We then show how a coach might use this approach and what they might consider before doing so.

\section{The use of creative works in coaching}

There is a paradox at the heart of approaches that use creative and expressive arts to work with clients in the 'logical and non-logical realms' (Buswick et al, 2010, p.53). The poet William Carlos Williams expresses this approach in Asphodel, as follows:

It is difficult

to get the news from poems

yet men die miserably every day

for lack of what is found there

Few responsible coaches would set themselves up as lifesavers. Yet we are engaged by clients looking for fuller, richer, more informed lives. Should we take Williams' hint and accept the possibility that "poetry has [the] capacity to change people"? (Bachkirova, 2011, p. 103) In this paper we consider how the "lack" referred to by Williams might be a fertile void in which client and coach might co-create insights into presenting issues. Whilst much coaching research (and consequently practice) relies on the fields of psychology and psychotherapy, it has tended to overlook a reliable and consistent source of data about what it means to be human. For 6000 years, since the Gilgamesh epic of Assyria, writers have cast light on the human condition. Bookshops bulge with stories of heroines and heroes facing disorienting dilemmas and resolving them through reflection and action (Tomlinson, 2020).

The therapeutic field makes wider use of art, and of writing in particular. Art therapy is defined as a treatment based on the interaction of the creator, the creation, and the therapist. It brings to awareness "repressed emotions and permits their exploration through the images created" (Freilich \& Shechtman, 2010). There is clearly a "continuity between...works of art and the everyday events, doings, and sufferings that are universally recognised to constitute experience" (Dewey, 1934, p. 2), and we recognize the fertile ground for coaching within that continuity. 
To date, at least two artists, Jennifer Gash (Gash, 2016), and Anna Sheather (Sheather, 2019), have identified that creative works have potential value in coaching. For Gash this resides in exploring the "relationship between the sensory and body psychotherapy" (p.43), whilst for Sheather it permits an emotional connectivity that "links, people, places and emotions to the present moment" (p.8). This accords with what Claxton describes as 'cross-talk', an interoceptive or sensory experience that involves communication between the body, behaviour, feeling and thinking (Claxton, 2015, p.158).

The use of poetry in coaching is not well established, although there are examples of how poetry can be used in business development. Morgan, writing about the use of poetry in business, suggests that 'a poem causes you to strip off the received ways of looking at things' (Morgan, Lange and Buswick, 2010). Such approaches help clients to reveal unconscious processes and, through the use of literary devices like metaphor, gain insights into presenting issues. Coaches support clients to use metaphor to reveal layered insights into their situation so they can, in a supported way, make meanings from the unconscious emerging stories.

Pennebaker (1997) articulated 'getting it out and writing it down' as a means of beginning to understand yourself. Therapeutic journaling is seen as a discipline in its own right and is used in clinical and non-clinical situations (Adams, 1998). Whilst, Bolton (2011) is well known for using poetry and writing as part of her work with therapy students. The commonality in the various disciplines is using writing to gain a better understanding of the self. If the aim of a coaching practice is to help the client have a better understanding of themselves, writing offers a way forward.

\section{Poetry Therapy}

Poetry Therapy has also been described as therapeutic writing and is a means of using poems and writing in a supportive facilitated way. Therapeutic in this instance is used in its broadest sense meaning towards developing wellbeing, which can include psychological healing. The National Associational of Poetry Therapy describes the benefits of poetry therapy as “...increased self and interpersonal awareness, increased sense of validation in voicing one's truth, and enhanced capacity to capture and reframe significant life stories" (NAPT, 2020). Similarly, The International Academy of Poetry Therapy (2020) views poetry therapy as an approach that allows a client time for exploration, consideration and reframing. This bears remarkable similarity to coaching processes, especially in the more psychological approaches such as 
person-centred and developmental coaching. The complementary aims of poetry therapy and coaching offer the coach creative and unique interventions to take into the coaching session.

Clients can write things on the paper that they would find hard to articulate and it is not unusual to see the client find surprising insights in their writing. This style of free writing is seen as precognitive writing where the client can be free of self-censorship. Allowing the writing to stand without any explanation or critique gives the client freedom to respond in any way they wish. Clients can be often anxious about poetry and have memories of poor experience of writing at school. However, in this style of approach the writing is purely for the client, they are not being asked to share it or to articulate any critique of the poem, in practice this has been described by clients as 'liberating'.

\section{Benefits of the approach}

In our experience the use of poetry in coaching can be developmentally beneficial in at least three ways. It can stimulate metacognition, enhance empathy, and generate new perspectives. Each is briefly discussed below, and illustrated with a case example.

\section{Potential Benefit \#1: Metacognition}

Metacognition refers to what we know about how we know, and is essential for self-knowledge, and therefore for development (Lyons and Bandura, 2018; Flavell, 1979). The development of metacognition is necessary for coaches as part of reflective practice (Van der Horst and Albertyn, 2018). Our responses to reading fiction can contribute to the development of metacognition as they can help us (i) understand how we see the world and why we see it that way (Koopman and Hakemulder, 2015; Newton, 1991), (ii) find new ways of thinking about it (Buswick, Morgan and Lange, 2005), and (iii) provoke 'subtle shifts' in our self-knowledge (Djikic et al., 2009, p. 28).

Metacognition depends on imagination (Archambault and Venet, 2007). Reading is useful because it initiates imagination as "a dance between thoughts and feelings [that] can enhance self-understanding and challenge us to live more fully as human beings" (Eva-Wood, 2008, p. 575) and lead to "moments of recognition or acknowledgement that signal change" (Miall and Kuiken, 2002, p.236). 
Case example. The poem Origins by Imelda Maguire (2011) focuses on the self and where we have come from. It is a poem that has relevance for any client who might be exploring aspects of the self, whilst simultaneously offering the coach an opportunity to work on their own development and reflexivity. The poem starts with the line 'I come from...' and hones in on all that is familiar, yet finishes with the acknowledgement that the familiar is changing, albeit we are formed by experience that will always shape our future:

I come from times that were changing

And carry a residue of times

That never will.

This poem has the potential to be used with both individual and work teams. For example, working with a group of young professionals who had travelled to work in the UK, it became apparent that by developing their professional identity they had lost a sense of who they were from a cultural perspective. Lines in this poem were used for the participants to identify their own origins and to make new poems or found poems, whereby text or narrative from other sources is reframed. The opportunity that this poem offers for exploration of what we know about our self, suggests that heeding Keats and 'read [ing] a certain page of full Poesy' might be more than just 'delicious diligent Indolence!' (Keats, 2002, p.62).

\section{Potential Benefit \#2: Empathy}

Even a limited period of reading and thinking about fiction can increase empathy. In imagining the emotions of fictional characters described by skillful authors, we engage our cognitive and affective thinking. We build a repertoire of others' possible responses to situations that are either unfamiliar to us, or experienced by those of a different gender, culture, age, or world view (Waxler, 2008, Djikic, Oatley et al, 2009, Plump and Van Buskirk, 2015, DillShackleford et al., 2016). It appears however that the reader needs to be "transported", or fully immersed in the work, for empathy to increase significantly (Bal and Veltkamp, 2013, Johnson, 2012). This points to the benefits of a close and frequent engagement with creative works.

Empathy matters for coaches if the questions we are asking are to be more than mere "interrogation" (Tschennen-Moran, 2014). It is an integral element of the emotional intelligence that Whitmore (2009) sees as crucial in building a coaching relationship. Clients who need to form effective relationships and accept differing points of view in the workplace may also 
need help developing empathy (Hind et al., 2009, Peltier, 2010). This is a complex and dynamic field of research which backs up Koopman and Hakemulder's "tentative support" (2015) for the positive effects of fiction upon empathy.

Case Example. A client who was struggling to manage their team, attended coaching after receiving negative feedback from her manager. The client struggled with women in her team, who she viewed as non-achieving and as "wasted talent" This frustration had eventually spilled over into a team meeting and she was reported to her line-manager. Robin Morgan's poem Pedestrian Women (Chavis and Weisberger, 2003) offered the client time to think about other women and ultimately herself. The lines below helped the client explore the team members in more depth.

But drained of all your preconceptions

you may discover the bowl inside --

a high-glazed hyacinth blue

that rushes to your heart...

The use of "drained of all your preconceptions" in the first line invited the client to use free writing to capture any responses she felt. In this type of writing, grammar, sentence construction and spelling are irrelevant. The purpose is for immediacy and an opportunity to write without inhibition. Following a period of writing the client is invited to reflect on the process and experience. She reflected on her expectations of herself and how she was projecting her fear of not achieving on others, seeing the woman as one dimensional and failing to achieve what she assumed was the only route to success. This activity reinforced the words of Anais Nin cited by Bolton in her foreword to Hedges (2005) "we don't see things as they are, we see them as we are". Here, the client embraced the opportunity to have a 'fertile void' a space, not usually available to her, enabling her to develop new insights. In this case the client decided to take some further coaching to work on areas in her life as a opposed to focusing on the challenges she had working with colleagues.

\section{Potential Benefit \#3: New perspectives}

Authors use a combination of observation, memory and imagination to shed light upon human actions and emotions (Oatley, 1999, 2016). Poetry can tell us about life in a way which is too often absent from dry academic writing (Threlfall, 2013, Van Buskirk et al., 2015). As literature is grounded in shared, recognizable experience and provokes imaginative approaches to making sense 
of the world, it can function as a thought laboratory for testing ideas about life (Oatley, 2016). Coaches and clients may find this approach more accessible than psychological and psychotherapeutic approaches. However, an understanding of how some of these approaches work will add a richness to the coach's repertoire.

Case example. A client is feeling stuck and feels that they have nothing left to offer their organisation. A poem of choice may be one that explores the clients feeling of having nothing left to offer. Emily Dickinson's poem "Hope" is the thing with feathers $(1975, \mathrm{p} 116)$ uses the metaphor of a bird to represent hope. This poem was used in a coaching session with the client. The client was invited to read the poem aloud and to respond to it in writing. This a core part of the process and is where some of the client's subconscious thoughts can flow on to the paper in a safe way. Whilst some clients can find reading aloud embarrassing, this element is to be encouraged as it allows the client to embody the poem. This can lead to an intimacy between the reader and writer that might be missed from a silent reading of the page. Embodying the poem and giving notice to the sensations and feelings that arise encourages the free writing and a release for the client.

In this instance the client found through the experience of writing that there was hope and he remembered previous experiences of where he felt he had nothing to offer and how he had transformed that into an opportunity. In this case he made the decision to leave his organisation as he realised that the organisation that had nothing left for him.

\section{Choosing and using poems}

It bears saying that a book of poetry is not a toolbox, no single poem has a pre-determined use, or inbuilt applicability to one task rather than another. Neither is the coach asking the client to 'decode' a poem in order to pass an English Literature exam. Part of the magic of poetry is the unique relationship between the reader and the poem. Whatever a poem elicits in the coach, it will elicit something different in a client.

There are numerous anthologies which aid the process of choosing, including The Poetry Pharmacy (Sieghart, 2017) and Being Human (Astley, 2011). These anthologies place the selected poems in categories that may be helpful (e.g., The stuff of Life or Living in Hope). There are a raft of other books and resources, a very useful one being the online resource, the Poetry Foundation (https://www.poetryfoundation.org). A coach who reads widely, 
and develops their critical and emotional responses to texts, will widen their choice of poems and select those which seem most apposite to the presenting issue. A coach who also writes will understand a range of prompts and encouragements, and will use these to help the client get their pen on the paper, free from any fear that their work is going to be assessed for its poetic value. This is essential if the client is to find a new language for the presenting issues, and in doing so unlock whatever is blocking progress

\section{On creating a fertile void}

The coach who chooses to work in this way will have established an empathetic relationship with the client and be willing to draw on their own lived experience. Furthermore, a readiness to move from the concrete to the abstract, and the willingness to live with uncertainty and ambiguity, will help the coach avoid what the Romantic Poet John Keats calls a "palpable design", (Keats, 2002, p. 58) by which we having mean a fixed outcome in mind rather than allowing the session to develop. Such an approach requires the coach to be comfortable with Keats' notion of "negative capability", his term for the ability to work with "uncertainties, Mysteries, doubts, without any irritable reaching after fact and Reason" (ibid, pp. 41-42).

The use of poetry and literature is not a coaching tool in the traditional sense. Using poetry and techniques from models of poetry therapy can be transformative for the client, and may also lead to surprising insights, which the client may find distressing. Holding this emotion, and allowing the client to sit with it, is part of the exploring and creating element of the process. This can be a challenge to a coach who works best using a formulaic, or goal-oriented approach in their coaching sessions. This approach works very well when a coach works with use of self and is able to see beyond the presenting issue. The coach responds from a 'felt sense' (Gendlin, 1962), with compassionate inquiry rather than from a hard fact. This point is taken further by Bachkirova (2011) when she discusses 'soft thinking' and slowing down. A coach who can offer clients this type of space in coaching sessions can help them enhance creativity and insight, which we think can be thought of as a fertile void. Poetry and literature are effective in opening this void and allowing insights. Engaging with poetry is an offer to the client to move beyond immediate concrete answers. It allows them to explore, and delve into, that creative space that can get squashed in the everyday demands of what William Wordsworth describes as a "world [that] is too much with us" (1959, p. 435). 
A coach who is interested in this approach should ask themselves if they can work without answers, with the unknown, with a softness and flow, where usual coaching tools stay in the toolbox. If this is not the case, we would suggest more conventional approaches may feel more secure for the coach and, most likely, the client.

Essentially, this is a reflective approach best supported by engaging in reflective activities, such as reading and creative writing. Supervisors of coaches who choose this work will be at ease with the unknown and have the ability to allow a slow unfurling of insights as opposed to immediate answers.

\section{Conclusion}

Poetry is powerful; it knows the human condition. This reflective approach to coaching draws on models from adult education as well as therapy. It depends on the coach's readiness to work - in the client's interest - in the 'logical and non-logical realms' (Buswick et al, 2010, p.53). For example, working with empathy, metacognition and allowing new ways of seeing the familiar. The coach who is comfortable in creating a fertile void to give the client space for creativity is one who can engage and use the expressive arts for their own benefit and development. If, as coaches, we work with the human condition then using poetry in coaching may offer the client and coach insights into parts of themselves that they may have previously been unable to articulate. While potentially troubling, these insights, handled with respect and caution, can lead to a reframing and new perspective on the client's issues and challenges.

\section{Acknowledgements}

The authors wish to thank Professor Tatiana Bachkirova, Claudia Filsinger, and Dr Carmelina Lawton-Smith for feedback on earlier drafts of this paper.

\section{References}

Adams, K. (1998) The Way of the Journal: A Journal Therapy Workbook for Healing. Sidran Traumatic Stress Ins.

Archambault, A. and Venet, M. (2007) Le développement de l'imagination selon Piaget et Vygotsky: d'un acte spontané à une activité consciente, Revue des sciences de l'éducation, 33(1), pp. 5-24. http://dx.doi.org/10.7202/016186ar 
Astley, N. (2011). Being Human, Bloodaxe

Bachkirova, T. (2011) Developmental coaching: working with the self. Maidenhead, Berkshire, England,McGraw-Hill/Open University Press

Bal, P. and Veltkamp, M. (2013) How Does Fiction Reading Influence Empathy? An Experimental Investigation on the Role of Emotional Transportation, PLOS ONE, 8(1). WorldCat.org. https://doi: 10.1371/journal.pone.0055341.

Bolton, G. (2011) Write yourself: Creative writing and personal development. Jessica Kingsley Publishers.

Buswick, T., Morgan, C. and Lange, K. (2005) Poetry in the boardroom: thinking beyond the facts, Journal of Business Strategy, 26(1), pp. 3440. https://doi.org/10.1108/02756660510575032

Chavis, G. G. and Weisberger, L. L. (2003) The healing fountain: Poetry therapy for life's journey. North Star Press of St. Cloud

Claxton, G. (2015) Intelligence in the flesh: why your mind needs your body much more than it thinks. Yale University Press.

Dill-Shackleford, K. E., Vinney, C. and Hopper-Losenicky, K. (2016) Connecting the dots between fantasy and reality: The social psychology of our engagement with fictional narrative and its functional value, Social and Personality Psychology Compass, 10(11), pp. 634-646. https://doi.org/10.1111/spc3.12274

Dickinson, E (1975) The Complete Poems, Faber and Faber. Also available at https://poets.org/poem/hope-thing-feathers-254

Djikic, M., Oatley, K., Zoeterman, S. and Peterson, J. (2009) On Being Moved by Art: How Reading Fiction Transforms the Self, Creativity Research Journal, 21(1), pp. 24-29. https://doi: 10.1080/10400410802633392

Eva-Wood, A. L. (2008) Does feeling come first? How poetry can help readers broaden their understanding of metacognition - Readers' emotional responses can enhance their metacognitive experiences and inform their literary analyses, Journal of adolescent \& adult literacy: a journal from the International Reading Association., 51(7), pp. 564-576. https://doi.org/10.1598/JAAL.51.7.4

Flavell, J. (1979) Metacognition and Cognitive Monitoring A New Area of Cognitive-Developmental Inquiry, American Psychologist, 34(10 ), pp. 906-911. https://psycnet.apa.org/doi/10.1037/0003-066X.34.10.906

Freilich, R. and Shechtman, Z. (2010) The contribution of art therapy to the social, emotional, and academic adjustment of children with learning disabilities, The Arts in Psychotherapy, 37(2), pp. 97-105. https://doi.org/10.1016/j.aip.2010.02.003.' 
Gash, J. (2017) Coaching Creativity: Transforming Your Practice, Oxford: Routledge

Gendlin, E. (1962) Experiencing and the Creation of Meaning: A Philosophical and Psychological Approach to the Subjective. Evanston, IL:

Nothwestern University Press

Hedges, D. (2005) (reprinted 2013 with amendments) Poetry, Therapy \& Emotional Life Radcliffe Publishing Ltd. London

Hind, P., Wilson, A. and Lenssen, G. (2009) Developing leaders for sustainable business, Corporate Governance: The international journal of business in society, 9(1), pp. 7-20. https://doi.org/10.1108/14720700910936029

International Academy of Poetry Therapy (2020). https://iapoetry.org/about/

Johnson, D. R. (2012) Transportation into a story increases empathy, prosocial behavior, and perceptual bias toward fearful expressions, Personality and Individual Differences, 52(2), pp. 150-155. https://doi.org/10.1016/j.paid.2011.10.005

Keats, J., Gittings, R. and Mee, J. (2002) Selected letters. Oxford world's classics [Rev. ed.] Oxford: Oxford University Press.

Koopman, E. and Hakemulder, F. (2015) Effects of Literature on Empathy and Self-Reflection: A Theoretical-Empirical Framework, Journal of Literary Theory, 9 (1) pp. 79-111 https://doi.org/10.1515/jlt-2015-0005

Lyons, P. R. and Bandura, R. P. (2018) Understanding metacognition: concepts supporting employee learning and growth, Human Resource Management International Digest, 26(6), pp. 44-46. https://doi.org/10.1108/HRMID-07-2018-0155

Miall, D. S. and Kuiken, D. (2002) A feeling for fiction: becoming what we behold, Poetics, 30(4), pp. 221-241. https://doi.org/10.1016/S0304422X(02)00011-6

Maguire, I. (2004) Shout If You Want Me To Sing; Summer Palace Press, County Donegal Ireland

Morgan, C., Lange, K. and Buswick, T. (2010) What poetry brings to business. Ann Arbor: University of Michigan Press.

National Associational of Poetry Therapy (2020). https://poetrytherapy.org

Newton, E. V. (1991) 'Developing Metacognitive Awareness: The Response Journal in College Composition', Journal of Reading, 34(6), pp. 476-78.

Oatley, K. (1999) Why fiction may be twice as true as fact: Fiction as cognitive and emotional simulation, Review of General Psychology, 3(2), pp. 101-117. https://doi.org/10.1037\%2F 1089-2680.3.2.101

Oatley, K. (2009) Communications to Self and Others: Emotional Experience and its Skills, Emotion Review, 1(3), pp. 206-213. https://doi: 10.1177/1754073909103588 
Peltier, B. (2010) The psychology of executive coaching: theory and application. 2nd ed. edn. New York: Routledge.

Pennebaker, J. W. (1997) Writing about emotional experiences as a therapeutic process, Psychological science. SAGE Publications Sage CA: Los Angeles, CA, 8(3), pp. 162-166.

Plump, C. and Van Buskirk, W. (2015) Roses Are Red, Money Is Green : A Resource Review of What Poetry Brings to Business, Journal of Management Education, 39(2), pp. 297-304. https://doi: $10.1177 / 1052562914536052$

Sheather, A. (2019) Coaching Beyond Words: Using Art to Deepen and Enrich Our Conversations, Oxford: Routledge

Sieghart, W. (2017) The Poetry Pharmacy, Penguin

Tomlinson, C. (2020) Using the Romantics to understand the imagination: A creative and original methodology for research into coaching, International Journal of Evidence Based Coaching and Mentoring. S14, pp.132-142. https://doi: 10.24384/rq4t-ny31

Tschennen-Moran, B. (2014) Skills and Performance Coaching, in Cox, E., Bachkirova, T. and Clutterbuck, D. (eds.) The Complete Handbook of Coaching. 2nd ed. London: Sage, pp. 201-214.

Threlfall, S. J. (2013) Poetry in action [research]. An innovative means to a reflective learner in higher education (HE), Reflective Practice, 14(3), pp. 360-367. https://doi.org/10.1080/14623943.2013.767232

Van der Horst, C. A. and Albertyn, R. M. (2018) The importance of metacognition and the experiential learning process within a cultural intelligence-based approach to cross-cultural coaching, SA Journal of Human Resource Management, 16(1), pp. 1-11. https://doi.org/10.4102/sajhrm.v16i0.951

Waxler, R. P. (2008) Changing Lives through Literature, PMLA, 123(3), pp. 678-683. https://doi.org/10.1632/pmla.2008.123.3.678

Whitmore, J. (2009) Coaching for performance. London: Nicholas Brealey.

Williams, W.C Asphodel https://poets.org/poem/asphodel-greeny-flowerexcerpt, accessed 26 October 2020

Wordsworth, W. (1959) Selected Poems. London: Wm. Collins Sons \& Co.

\author{
Author Contacts \\ Deborah Humphrey \\ Oxford, UK \\ E: deborah.humphrey4@gmail.com
}


Carl Tomlinson

Oxford, UK

E: carltomlinson1967@gmail.com 